\title{
Prices in the Current Expansion
}

HE ECONOMY has been expanding rapidly, following the moderated pace of activity in early 1967. Upward pressure on prices, resulting from growth in demand relative to supply and reinforced by increasing costs of production, has been felt in various markets.

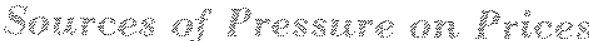

Recent price movements have reflected both rapid expansion in spending and strong cost pressures. Total spending has risen at an 8.5 per cent annual rate since mid-1967, whereas the growth in real output is estimated to be at about a 4.5 per cent rate. Although some of the increase in spending has been needed to utilize previously idle resources, the rate of expansion has been unusually rapid, causing some prices to move up. Also, in 1965 and 1966 some wages and other resource prices could not rise in response to the increase in demand. However, at times of renegotiation these prices have been marked up, placing further upward pressure on other prices.

The upward surge in spending has been fostered by stimulative fiscal and monetary actions. The strong expansionary force of fiscal actions moderated a bit in the second half; the deficit in high-employment budget increased from $\$ 4$ billion in the second half of 1966 to $\$ 12$ billion in the first half of 1967 , but remained essentially unchanged during the rest of the year. However, the maintainance of a very strong government demand in the second half, as private demand accelerated, contributed to upward pressure on prices.

Monetary actions were also a strong upward force on spending and prices during late 1967. Bank reserves and bank credit rose rapidly during the year. The money supply expanded about 6 per cent in the year, compared with a 2.4 per cent rate of growth from 1957 to 1966 .

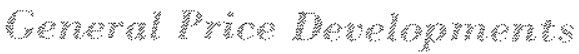

All major measures of prices have demonstrated rapid upward movements recently. The broadest measure of prices, the GNP deflator, increased at an accelerated 3.8 per cent annual rate in the second half of 1967 , after having risen at a 2.3 per cent rate in the first half. Consumer prices increased at a 2.3 per cent rate during the first six months of the year but accelerated to a 4 per cent rate after mid-year. Wholesale industrial prices increased at a 2.5 per cent rate from June to November, after having increased at a 1 per cent rate during the previous six months.

Aggregate measures of prices, computed from numerous goods and services in many markets, are not indicative of movements of particular prices in specific markets. An examination of some specific price movements gives a better perspective of developments than a review of overall indexes.

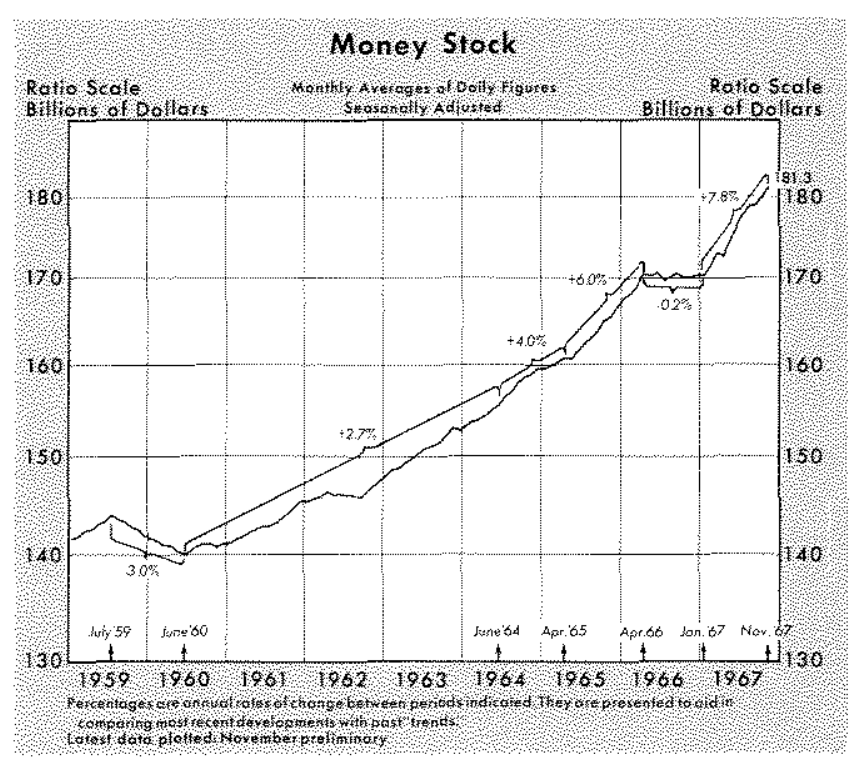




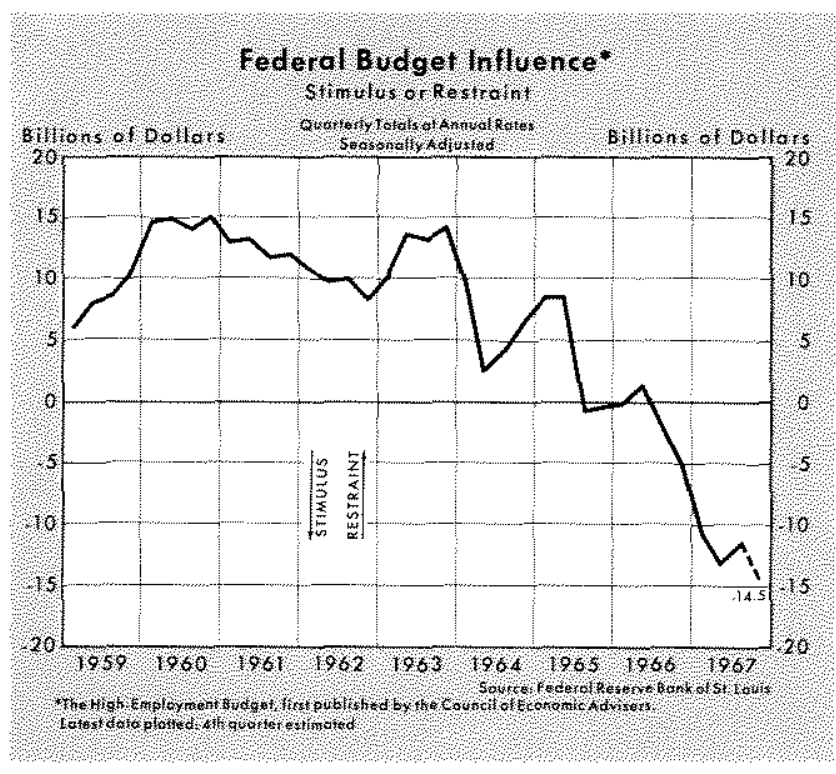

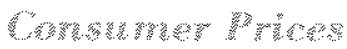

Personal services account for over one-third of consurner purchases. Since most services are produced with primarily human effort, costs of services tend to reflect wage and salary increases. In addition, the high proportion of labor input makes increases in efficiency and quality difficult to measure. The prices of services have increased at about a 3 per cent average rate over the past decade, and have been a major factor in the upward trend of consumer prices in the past year. The prices of services increased at about the trend rate through the first half but accelerated later in the year. The acceleration reflected in part rapid increases in the prices of medical care and household services.

In contrast to the prices of services, food prices fluctuated sharply in 1967 . Since the demand for food grows at a relatively stable rate over time, most

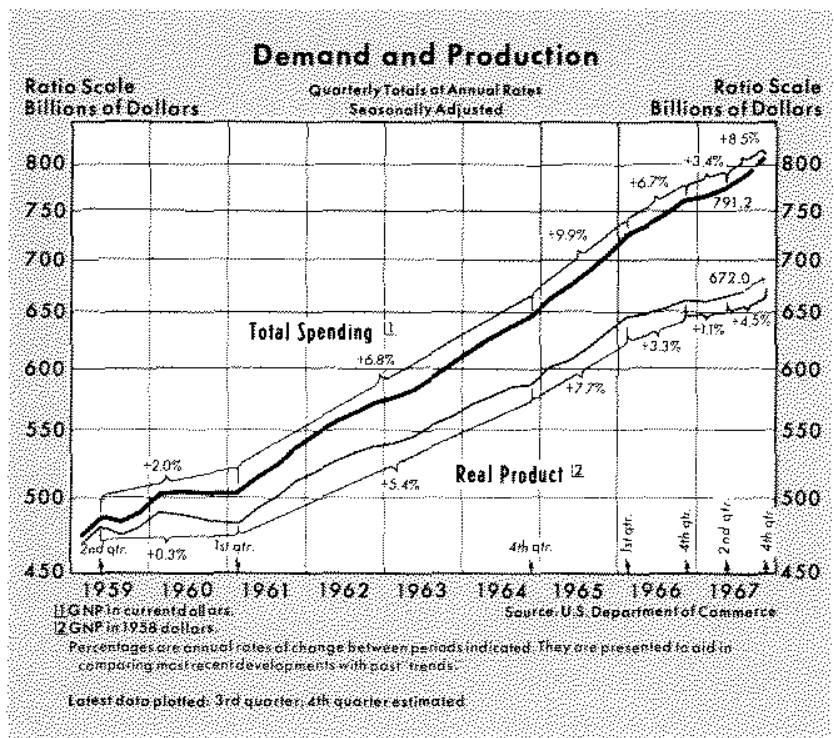

changes in the prices of food have been caused primarily by supply factors. Food prices fell during the first half of 1967 as a result of an increased supply of farm products, which probably reflected the response of producers to rapid increases in food prices in 1966. During the late summer and early fall food prices again fell sharply, reflecting large harvests.

Prices of commodities other than food increased at a 2.4 per cent rate during the first eight months of the year. Since August the prices of these commodities have risen at a sharp 6.4 per cent rate; prices of both durable and nondurable goods advanced. Used car prices accounted for much of the increase in durable goods through the first half of the year, and in the fall, as the 1968 models reached the market, new car prices increased significantly. Large increases in the prices of apparel contributed to the acceleration of nondurable prices in the second half.

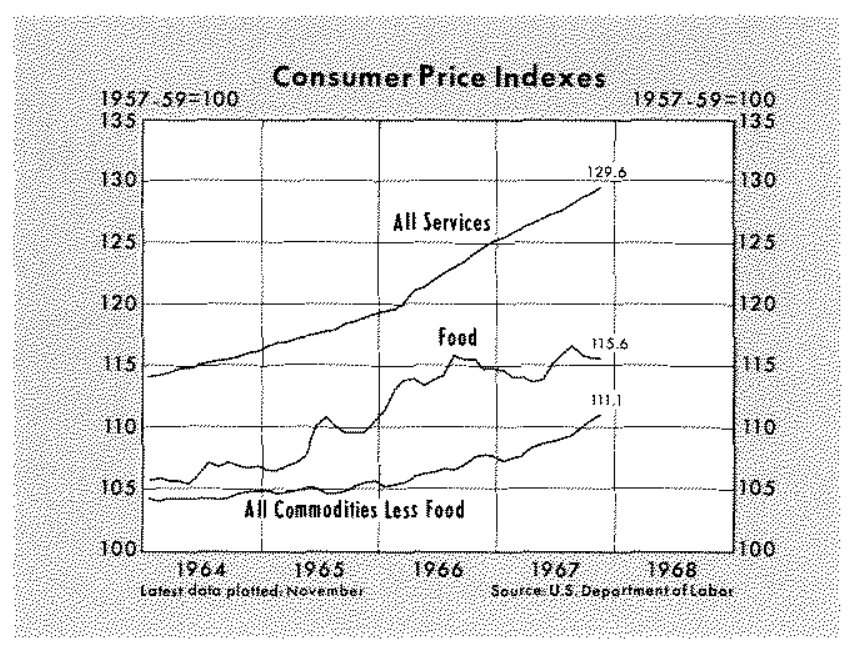

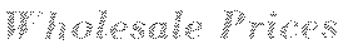

Wholesale prices declined early in the year, rose rapidly during the spring and early summer, and remained about unchanged late in the year. This pattern primarily reflected movements in prices of farm products and processed foods, and these price changes in turn reflected supply factors.

The prices of industrial crude materials declined through most of the year, but showed some increases in late fall. The movement in these prices paralleled changes in industrial production and largely reflected sudden changes in demand. As industrial production moderated in late 1966 and then fell in early 1967 , the abrupt decrease in demand for raw material put downward pressure on the prices of these items. As production began expanding near mid-1967, the prices of raw materials began rising after a brief lag.

In contrast to the prices of raw materials, quota- 


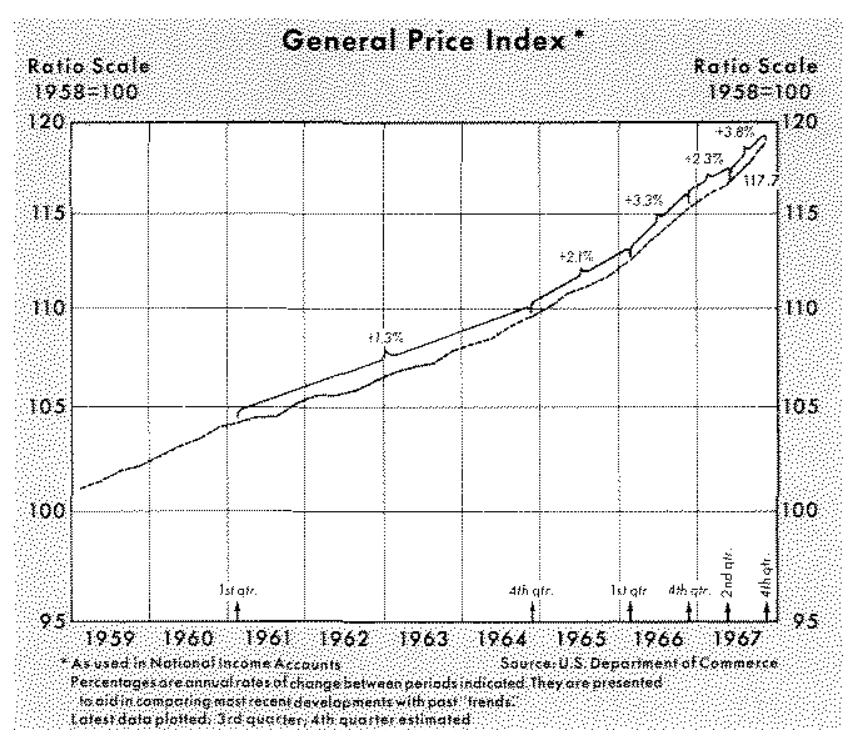

tions on industrial finished goods rose throughout the year. Cost factors significantly contributed to the rise. Cost increases during the year resulted largely from the price developments of the previous year. Wages and other resource prices set by contracts could not adjust in 1965 and 1966 to increasing demand. As contracts expired this past year, wages and other resource prices rose.

Increases in wage rates not matched by increases in productivity lead to higher labor costs per unit of production. As industrial production fell in the first half of 1967 and some firms attempted to maintain their labor force, productivity was sharply reduced. This, coupled with the increases in wages, led to a significant increase in the labor cost per unit of manufacturing output. The increased labor cost placed a strong upward pressure on the price of output.

The extent to which prices could be increased, however, depended on the strength of demand. Large wage increases were experienced in industries producing finished consumer nondurables. The higher costs, in addition to strong consumer demand for nondurable goods, accounted for large increases in the prices of industrial nondurable consumer goods. Industrial finished consumer durables showed a more moderate rate of increase in prices. As a whole, the prices of in-

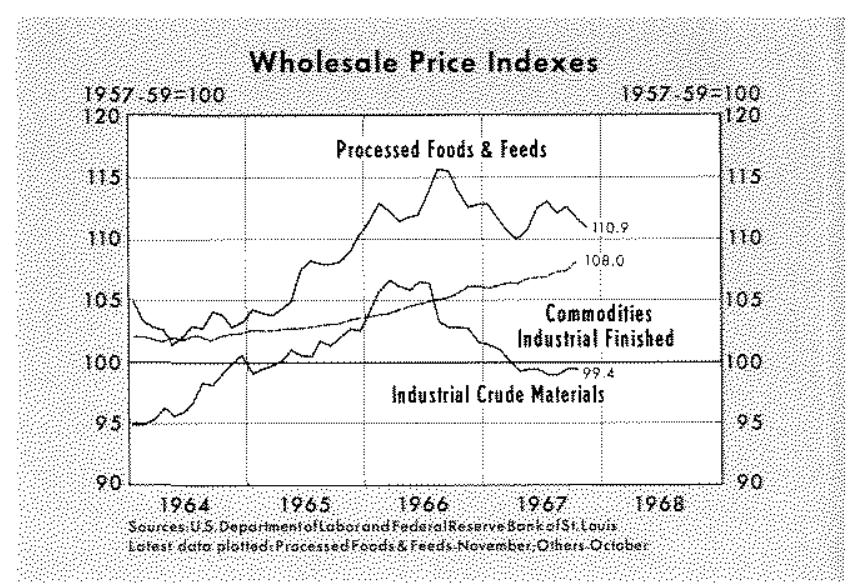

dustrial finished commodities increased at a 1.3 per cent rate in the first half of the year. They have risen at a 2.3 per cent rate since mid-year in response to the acceleration of demand.

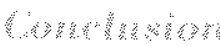

With the exception of food and farm products, all major categories of goods and services have recently been exhibiting rising prices. The rapid expansion of demand for goods and services in conjunction with increasing costs of production has been the cause of the increases. Price developments in the coming year depend on the nature and relative strength of these two forces.

There is little indication that the demand for goods and services will moderate soon. Both monetary and fiscal actions have been expansionary and may have their heaviest impact with a brief lag. Spending for investment continues to increase as residential construction expands and businesses increase their rate of inventory accumulation. Plant and equipment expenditure probably will accelerate next year, after remaining essentially unchanged in 1967. Unused industrial capacity is a potential brake to price pressure caused by increasing demand; however, shortages are developing in some resource markets such as that for skilled labor. The future expansion of demand relative to production will determine what happens to prices, in both the product and resource markets. 